OPEN ACCESS

Edited by: Azzam Maghazachi, University of Sharjah, United Arab Emirates

Reviewed by: Urszula Krzych, Walter Reed Army Institute of Research, USA Bruno Laugel, Cardiff University, UK

*Correspondence: Seung Hyun Han shhan-mi@snu.ac.kr

Specialty section: This article was submitted to Immunotherapies and Vaccines,

a section of the journal

Frontiers in Immunology

Received: 06 August 2016 Accepted: 04 October 2016 Published: 20 October 2016

Citation:

Kim SK, Yun C-H and Han SH (2016) Induction of Dendritic Cell

Maturation and Activation by a Potential Adjuvant 2-Hydroxypropyl- $\beta$-Cyclodextrin. Front. Immunol. 7:435. doi: 10.3389/fimmu.2016.00435

\section{Induction of Dendritic Cell Maturation and Activation by a Potential Adjuvant, 2-Hydroxypropyl-p-Cyclodextrin}

\author{
Sun Kyung Kim ${ }^{1}$, Cheol-Heui Yun ${ }^{2}$ and Seung Hyun Han ${ }^{1 *}$ \\ ${ }^{1}$ Department of Oral Microbiology and Immunology, DRI, and BK21 Plus Program, School of Dentistry, Seoul National \\ University, Seoul, South Korea, ${ }^{2}$ Department of Agricultural Biotechnology, Research Institute for Agriculture and Life \\ Sciences, Seoul National University, Seoul, South Korea
}

2-Hydroxypropyl- $\beta$-cyclodextrin (HP- $\beta-\mathrm{CD})$ is a chemically modified cyclic oligosaccharide produced from starch that is commonly used as an excipient. Although HP- $\beta-C D$ has been suggested as a potential adjuvant for vaccines, its immunological properties and mechanism of action have yet to be characterized. In the present study, we investigated the maturation and activation of human dendritic cells (DCs) treated with HP- $\beta-C D$. We found that DCs stimulated with HP- $\beta$-CD exhibited a remarkable upregulation of costimulatory molecules, MHC proteins, and PD-L1/L2. In addition, the production of cytokines, such as TNF- $\alpha$, IL-6, and IL-10, was modestly increased in DCs when treated with HP- $\beta-C D$. Furthermore, HP- $\beta-C D$-sensitized DCs markedly induced the proliferation and activation of autologous T lymphocytes. HP- $\beta-C D$ also induced a lipid raft formation in DCs. In contrast, filipin, a lipid raft inhibitor, attenuated HP- $\beta$-CD-induced DC maturation, the cytokine expression, and the T lymphocyte-stimulating activities. To determine the in vivo relevance of the results, we investigated the adjuvanticity of $\mathrm{HP}-\beta-\mathrm{CD}$ and the modulation of DCs in a mouse footpad immunization model. When mice were immunized with ovalbumin in the presence of HP- $\beta-C D$ through a hind footpad, serum ovalbumin-specific antibodies were markedly elevated. Concomitantly, DC populations expressing CD11c and MHC class II were increased in the draining lymph nodes, and the expression of costimulatory molecules was upregulated. Collectively, our data suggest that HP- $\beta-C D$ induces phenotypic and functional maturation of DCs mainly mediated through lipid raft formation, which might mediate the adjuvanticity of HP- $\beta-C D$.

Keywords: 2-hydroxypropyl- $\beta$-cyclodextrin, vaccine adjuvants, dendritic cells, maturation, lipid raft

\section{INTRODUCTION}

Cyclodextrins are cyclic oligosaccharides composed of sugar molecules. These oligosaccharides consist of 6,7 , or $8 \alpha$-D-glucopyranose units bound via $\alpha$-1,4-glycosidic linkages, namely, $\alpha$-, $\beta$-, or $\gamma$-cyclodextrin, respectively. Cyclodextrins exhibit a bucket-shaped structure with a hydrophobic central cavity and a hydrophilic exterior (1). Cyclodextrins can efficiently form water-soluble inclusion complexes with hydrophobic molecules, which enhances the solubility and bioavailability of many insoluble compounds $(2,3)$. In addition, cyclodextrins improve and prolong the medicinal 
effects of drugs by controlling compound release, increasing their stability, and regulating the metabolism of the incorporated molecules (4). Due to these physicochemical properties, cyclodextrins are commonly utilized as excipients of pharmaceutical agents, food products, and cosmetics.

$\beta$-Cyclodextrin and some of its derivatives are widely used additives of commercial drugs because they are easy to produce, belong to generally recognized as safe (GRAS) materials for humans, and have improved solubility compared with the other cyclodextrins $(4,5)$. 2-Hydroxypropyl- $\beta$-cyclodextrin (HP- $\beta$-CD) is a chemically modified derivative of $\beta$-cyclodextrin that exhibits an enhanced safety profile compared with its naturally occurring parent compound (4). HP- $\beta$-CD is used as an excipient for cardiac dysrhythmia, inflammation, and fungal disease medications (6). Furthermore, HP- $\beta$-CD has been proposed as a vaccine adjuvant because it markedly enhances humoral immune responses to an influenza vaccine without any adverse effects (7). However, the immunological properties and action mechanism of HP- $\beta-C D$ need to be further characterized for the human use.

Dendritic cells (DCs) are professional antigen-presenting cells that bridge the innate and adaptive immunities. Immature DCs are characterized by high endocytic activity coincident with a low expression of costimulatory molecules and cytokines (8). When immature DCs meet microbial antigens or damage-associated molecular patterns, they begin the process of maturation $(8,9)$. This process is accompanied by upregulation of (i) MHC associated with the antigen; (ii) costimulatory molecules including CD40, CD80, and CD86; and (iii) inflammatory cytokines such as IL-12, IL-6, and TNF- $\alpha$ (10). These phenotypic changes optimize conditions for T lymphocyte activation and differentiation $(11,12)$. Since mature DCs potently stimulate adaptive immunity better than immature DCs, many vaccine adjuvants currently under development are designed to efficiently induce functional maturation and activation of DCs (13-15). In the present study, we investigated immunological function of HP- $\beta-C D$ by determining its ability to mature and activate DCs leading to the induction of adaptive immunity.

\section{MATERIALS AND METHODS}

\section{Reagents and Chemicals}

2 -Hydroxypropyl- $\beta$-cyclodextrin was purchased from SigmaAldrich (Saint Louis, MO, USA). Ficoll-Paque PLUS was obtained from GE Healthcare (Uppsala, Sweden). Fetal bovine serum (FBS) was purchased from GIBCO (Grand Island, NY, USA). RPMI-1640 medium and HyClone ${ }^{\mathrm{TM}}$ penicillin-streptomycin solution were from HyClone (Logan, UT, USA). Antihuman CD14 magnetic beads (clone: МФP9) and anti-human CD3 magnetic beads (clone: HIT3a) were purchased from BD Biosciences (San Diego, CA, USA). Recombinant human granulocyte macrophage-colony stimulating factor (GM-CSF) and IL-4 were purchased from R\&D Systems (Minneapolis, $\mathrm{MN}$, USA) and CreaGene (Sungnam, Korea), respectively. Recombinant murine GM-CSF was obtained from CreaGene. $3,3^{\prime}, 5,5^{\prime}$-Tetramethylbenzidine (TMB) substrate and enzymelinked immunosorbent assay (ELISA) kits for the quantification of human TNF- $\alpha$, IL-6, IL-12p70, and IL-10, and mouse TNF- $\alpha$ and IL-6 were purchased from BioLegend (San Diego, CA, USA). 5,6-Carboxyfluorescein diacetate succinimidyl ester (CFDA-SE) and the Vybrant ${ }^{\circledR}$ Alexa Fluor ${ }^{\circledR} 594$ lipid raft-labeling kit were obtained from Molecular Probes (Eugene, OR, USA). Filipin, bovine serum albumin (BSA), 2,2,2-tribromoethanol, 2-methyl2-butanol, ovalbumin (OVA), and red blood cell (RBC)-lysis buffer were purchased from Sigma-Aldrich. Luria Bertani broth and Bacto ${ }^{\mathrm{TM}}$ Agar were purchased from BD Biosciences. FITC-labeled anti-human CD80 (clone: 2D10), PE-labeled anti-human CD83 (clone: HB15e), APC-labeled anti-human CD86 (clone: IT2.2), APC-labeled anti-PD-L1 (clone: 29E.2A3), PE-labeled anti-human PD-L2 (clone: 24F.10C12), APC-labeled anti-human CD25 (clone: BC96), PE-labeled anti-human CD4 (clone: RPA-T4), and PE-labeled anti-human CD8 (clone: RPAT8) antibodies were purchased from BioLegend. FITC-labeled anti-human HLA-DR, DP, DQ (clone: Tu39) antibody for MHC class II, FITC-labeled anti-mouse CD86 (clone: GL-1) antibody, PE-labeled anti-mouse CD80 (clone: 16-10A1) antibody, PerCPlabeled anti-mouse CD11c (clone: N418) antibody, and FITClabeled anti-mouse I- $\mathrm{A}^{\mathrm{b}}$ (clone: 25-9-17) antibody for $\mathrm{MHC}$ class II were obtained from BD Biosciences. All isotype-matched antibodies were purchased from BD Biosciences or BioLegend. Horseradish peroxidase (HRP)-conjugated anti-mouse total IgG, anti-mouse IgG1, and anti-mouse IgG2a were purchased from Southern Biotech (Birmingham, AL, USA).

\section{Preparation of Human Monocyte-Derived DCs}

Human peripheral blood samples donated by healthy adult male subjects $(n=15)$ were provided from the Korean Red Cross (Seoul, Korea) after obtaining informed consent. All experiments using human blood were conducted under the approval of the Institutional Review Board of Seoul National University. The peripheral blood was diluted in phosphate-buffered saline (PBS) and overlaid on the Ficoll-Paque PLUS, and peripheral blood mononuclear cells (PBMCs) were isolated by densitygradient centrifugation as previously described $(16,17)$. PBMCs were washed with PBS three times to remove platelets and the remaining Ficoll. To isolate $\mathrm{CD} 14^{+}$monocytes, PBMCs were incubated with anti-human CD14 magnetic beads for $30 \mathrm{~min}$ at room temperature. The cells were separated on a magnetic field, and then $\mathrm{CD} 14^{+}$cells were enriched by positive selection. $\mathrm{CD} 14^{+}$ monocytes were suspended at a concentration of $2 \times 10^{6}$ cells/ $\mathrm{ml}$ in RPMI-1640 medium supplemented with 10\% FBS and 1\% penicillin-streptomycin solution. The isolated monocytes were differentiated into immature DCs in the presence of human recombinant GM-CSF (5 ng/ml) and IL-4 (10 ng/ml) for 6 days. Cell culture medium supplemented with GM-CSF and IL-4 was added every 3 days.

\section{Preparation of HKEC}

Escherichia coli BL21 (DE3) strain obtained from Stratagene (La Jolla, CA, USA) was cultured in Luria Bertani broth at $37^{\circ} \mathrm{C}$ until reaching mid-log phase and then harvested by centrifugation. The harvested bacterial cells were resuspended in PBS and killed 
by heating at $60^{\circ} \mathrm{C}$ for $1 \mathrm{~h}$. To confirm the complete killing, the heat-treated E. coli was plated onto Luria Bertani agar plates and cultured overnight at $37^{\circ} \mathrm{C}$. No bacterial colonies were observed.

\section{Analysis of DC Phenotypes}

Mouse BM-DCs $\left(5 \times 10^{5}\right.$ cells $\left./ \mathrm{ml}\right)$ were stimulated with either $\mathrm{HP}-\beta-\mathrm{CD}(0,0.1$, or $1 \mathrm{mg} / \mathrm{ml})$ or LPS $(100 \mathrm{ng} / \mathrm{ml})$ in the presence of murine GM-CSF $(10 \mathrm{ng} / \mathrm{ml})$ for $24 \mathrm{~h}$. Human monocytederived DCs $\left(2.5 \times 10^{5}\right.$ cells $\left./ \mathrm{ml}\right)$ were stimulated with either $\mathrm{HP}-\beta$-CD $(0,0.1,0.3$, or $1 \mathrm{mg} / \mathrm{ml})$ or HKEC $\left(1 \times 10^{7} \mathrm{CFU} / \mathrm{ml}\right)$ in the presence of GM-CSF $(2.5 \mathrm{ng} / \mathrm{ml})$ and IL-4 $(5 \mathrm{ng} / \mathrm{ml})$ for $24 \mathrm{~h}$. The unstimulated or stimulated DCs were then stained with fluorochrome-conjugated monoclonal antibodies specific to CD80, CD83, CD86, MHC class II, PD-L1, or PD-L2 for $30 \mathrm{~min}$ on ice, and then the cells were washed once with PBS. The geometric mean fluorescence intensity (MFI) of each group of DCs was obtained by flow cytometric analysis. More than 8,500 events were acquired for each group, and cell debris and dead cells were gated out. Phenotypes of DCs were analyzed using flow cytometry with FACSCalibur (BD Biosciences) and FlowJo software (TreeStar, San Carlos, CA, USA).

\section{Cytokine Quantification}

The levels of cytokines produced by DCs were quantified by ELISA, as previously described (18). Briefly, mouse BM-DCs $\left(5 \times 10^{5}\right.$ cells $\left./ \mathrm{ml}\right)$ were stimulated with either HP- $\beta$-CD $(0$, 0.1 , or $1 \mathrm{mg} / \mathrm{ml})$ or LPS $(100 \mathrm{ng} / \mathrm{ml})$ in the presence of murine GM-CSF $(10 \mathrm{ng} / \mathrm{ml})$ for $24 \mathrm{~h}$. Human monocyte-derived DCs $\left(2.5 \times 10^{5} \mathrm{cells} / \mathrm{ml}\right)$ were stimulated with either $\operatorname{HP}-\beta$-CD $(0,0.1$, 0.3 , or $1 \mathrm{mg} / \mathrm{ml})$ or HKEC $\left(1 \times 10^{7} \mathrm{CFU} / \mathrm{ml}\right)$ in the presence of GM-CSF $(2.5 \mathrm{ng} / \mathrm{ml})$ and IL-4 $(5 \mathrm{ng} / \mathrm{ml})$ for $24 \mathrm{~h}$. The levels of TNF- $\alpha$, IL-6, IL-12p70, and IL-10 in the culture supernatants were measured by ELISA kits according to the manufacturers' instructions.

\section{Coculture of DCs with Autologous T Lymphocytes}

To isolate $\mathrm{CD}^{+} \mathrm{T}$ lymphocytes, $\mathrm{CD} 14^{+}$monocyte-depleted PBMCs were incubated with anti-human CD3 magnetic beads for $30 \mathrm{~min}$, and then $\mathrm{CD}^{+} \mathrm{T}$ lymphocytes were enriched by positive selection. The isolated $\mathrm{CD}^{+} \mathrm{T}$ lymphocytes were labeled with $10 \mu \mathrm{M}$ CFDA-SE for $15 \mathrm{~min}$ at $37^{\circ} \mathrm{C}$ and washed with PBS. Immature DCs $\left(2.5 \times 10^{5}\right.$ cells $\left./ \mathrm{ml}\right)$ were stimulated with either HP- $\beta$-CD $(0,0.1,0.3$, or $1 \mathrm{mg} / \mathrm{ml})$ or HKEC $\left(1 \times 10^{7} \mathrm{CFU} / \mathrm{ml}\right)$ in the presence of GM-CSF $(2.5 \mathrm{ng} / \mathrm{ml})$ and IL-4 (5 ng/ml) for $16 \mathrm{~h}$. After removal of the culture supernatant, the DCs $\left(5 \times 10^{4}\right.$ cells) were cocultured with carboxyfluorescein succinimidyl ester (CFSE)-labeled autologous $\mathrm{CD}^{+} \mathrm{T}$ lymphocytes $\left(5 \times 10^{4}\right.$ cells $)$ for 4-5 days. To analyze DC-mediated proliferation and activation of T lymphocyte subsets, the cells were stained with anti-human CD4, anti-human CD8, or anti-human CD25 antibodies and then analyzed by flow cytometry.

\section{Analysis of Lipid Raft Formation}

Dendritic cells $\left(2.5 \times 10^{5}\right.$ cells $\left./ \mathrm{ml}\right)$ were stimulated with HP- $\beta$-CD $(1 \mathrm{mg} / \mathrm{ml})$ in the presence or absence of filipin $(30 \mu \mathrm{g} / \mathrm{ml})$ for $45 \mathrm{~min}$. Cell staining was performed with the lipid raftlabeling kit according to the manufacturer's instructions. Briefly, unstimulated or HP- $\beta$-CD-stimulated DCs were washed once with ice-cold PBS and stained with Alexa Fluor ${ }^{\circledR}$ 594-conjugated CTB conjugate for $10 \mathrm{~min}$ on ice. The DCs were washed once with ice-cold PBS and incubated with rabbit serum containing anti-CTB antibodies for $10 \mathrm{~min}$ on ice to crosslink lipid rafts on the surface of the DCs. Formation of lipid raft on the DCs was analyzed by confocal laser scanning microscopy (Carl Zeiss MicroImaging GmbH, Jena, Germany). Fluorescence intensity of DCs was analyzed by ZEN software, Lite Edition (Carl Zeiss, Oberkochen, Germany).

\section{Immunization with OVA Plus HP- $\beta-C D$ in Mice}

Seven-week-old male C57BL/6 mice were purchased from Orient Bio (Sungnam, Korea) and maintained in a specific pathogen-free animal facility. All experiments using animals were conducted under the approval of the Institutional Animal Care and Use Committee of Seoul National University. Care and treatment of the animals were carried out in accordance with the approved guidelines. Mice were anesthetized by intraperitoneal injection of Avertin (2,2,2-tribromoethanol and 2-methyl-2-butanol) and administered with $20 \mu \mathrm{g}$ OVA with or without $3 \mathrm{mg}$ HP- $\beta$-CD through a hind footpad. The mice were maintained for $24 \mathrm{~h}$ or 7 days and sacrificed to obtain the draining lymph nodes and the blood, respectively.

\section{Analysis of DC Activation in the Draining Lymph Nodes}

Twenty-four hours after the immunization with OVA in the presence or absence of HP- $\beta$-CD, draining lymph nodes, including popliteal and inguinal lymph nodes, were harvested and dissociated into a single cell suspension on a cell strainer (BD Biosciences). To analyze DC populations in the lymph nodes, the cells were stained with fluorochrome-conjugated antibodies specific to CD11c, MHC class II, CD86, and CD80 at $4^{\circ} \mathrm{C}$ for 30 min. CD $11 \mathrm{c}^{+} \mathrm{MHC}$ class $\mathrm{II}^{+}$cells in the lymph nodes and their phenotypic changes upon the administration of OVA in the presence or absence of HP- $\beta$-CD were analyzed by flow cytometry using FACSVerse (BD Biosciences).

\section{Preparation of Mouse Bone Marrow-Derived DCs}

Bone marrow-derived DCs (BM-DCs) were generated as previously described (19), with minor modifications. Briefly, BM cells were isolated from mouse femurs and tibias, and the RBCs were lysed with the RBC lysis buffer. Isolated BM cells were suspended in RPMI-1640 medium supplemented with 10\% FBS and 1\% penicillin-streptomycin solution and plated in petri dishes at $4 \times 10^{5}$ cells $/ \mathrm{ml}$. The BM cells were differentiated into immature DCs in the presence of murine recombinant GM-CSF $(20 \mathrm{ng} / \mathrm{ml})$ for 7 days. Cell culture medium supplemented with GM-CSF was added every 4 days. 


\section{Statistical Analysis}

The statistical significance of differences between the experimental groups and the control group was analyzed using Student's $t$-test. $P$-values less than 0.05 were considered statistically significant. Results are presented as mean value \pm SD or SEM.

\section{RESULTS}

\section{HP- $\beta$-CD Induces Maturation of Human Monocyte-Derived DCs}

Maturation of DCs is an essential process for activating antigen-specific adaptive immunity and includes the upregulation of costimulatory molecules, MHC class I/II, and certain cytokines (12). Thus, we first examined the effects of HP- $\beta-C D$ on the phenotypic maturation and cytokine production in human monocyte-derived DCs. Notably, HP- $\beta$-CD was not cytotoxic to DCs at concentrations up to $1 \mathrm{mg} / \mathrm{ml}$ (Figure S1A in Supplementary Material). Stimulation with HP- $\beta$-CD remarkably augmented the expression of costimulatory molecules, such as CD80, CD83, and CD86 (Figures 1A,D), together with MHC class II (Figures 1B,E). Additionally, HP- $\beta$-CDtreated DCs exhibited increased expression of inhibitory molecules, such as PD-L1 and PD-L2 (Figures 1C,F). Moreover, HP- $\beta$-CD weakly increased the expression of proinflammatory cytokines, including TNF- $\alpha$ and IL-6, in a dose-dependent manner (Figures 1G,H). Furthermore, HP- $\beta$-CD treatment slightly increased IL-10 expression in DCs (Figure 1I), and IL-12p70 was not detected in the culture supernatant of HP- $\beta$ CD-treated DCs (data not shown). These results suggest that HP- $\beta$-CD upregulates the expression of maturation markers coincident with weak induction of cytokines in human monocyte-derived DCs.

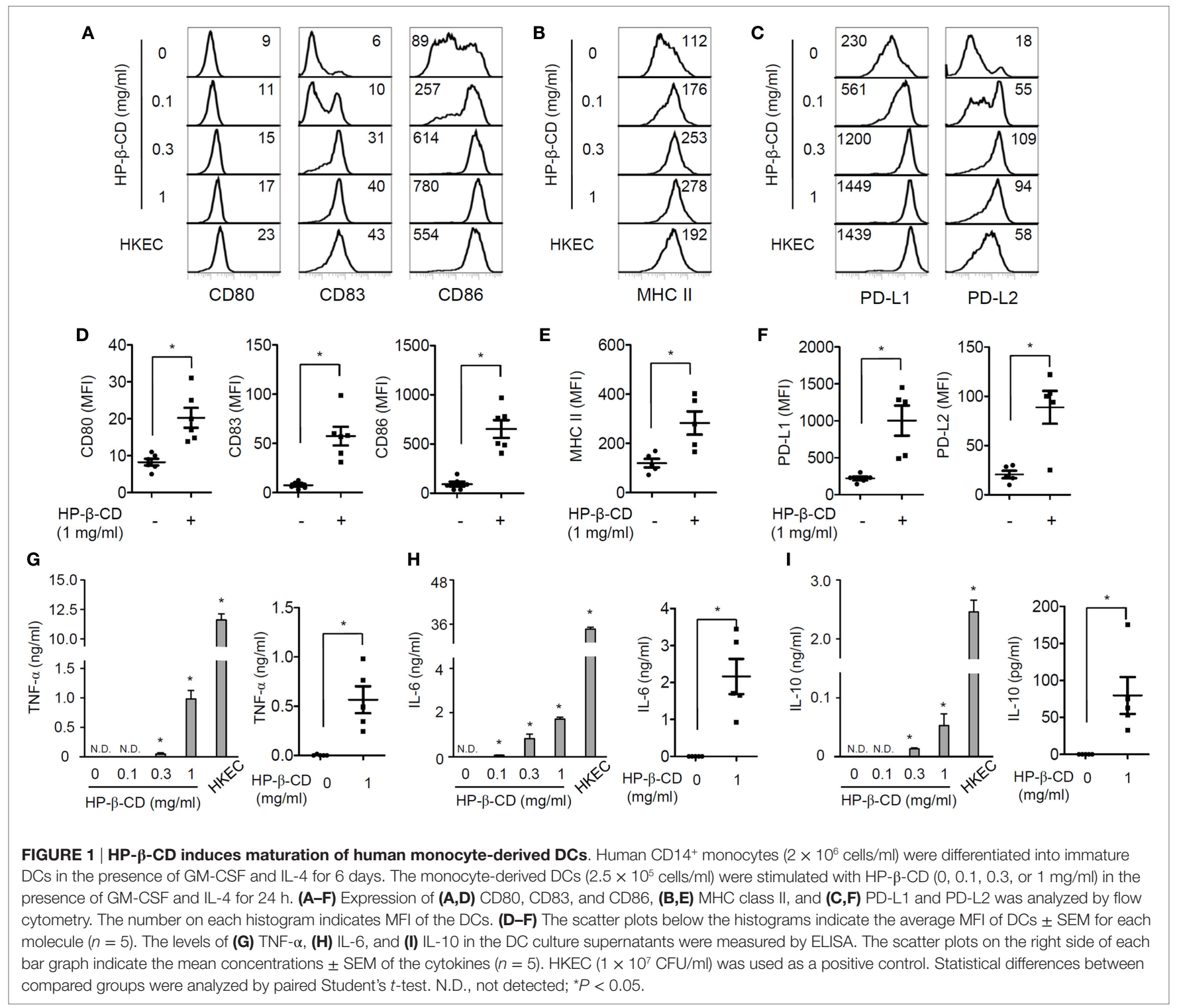




\section{HP- $\beta$-CD-Sensitized DCs Elicit Autologous T Lymphocyte Proliferation and Activation}

To examine whether HP- $\beta$-CD potentiates the T lymphocyteactivating ability of DCs, unstimulated or HP- $\beta$-CD-stimulated DCs were cocultured with autologous $\mathrm{T}$ lymphocytes, and the extents of $\mathrm{T}$ lymphocyte proliferation and activation were analyzed. HP- $\beta$-CD-sensitized DCs significantly induced $\mathrm{T}$ lymphocyte proliferation and CD25 expression, an activation marker of $\mathrm{T}$ lymphocytes (Figures 2A,B). The enhancement of proliferation and CD25 expression was observed in $\mathrm{CD}^{+}$ T lymphocytes but not in CD8 ${ }^{+} \mathrm{T}$ lymphocytes (Figures 2C,D). However, HP- $\beta$-CD did not directly enhance the proliferative activity or CD25 expression of the Tlymphocytes, indicating that HP- $\beta$-CD requires the help of DCs to activate T lymphocytes
(Figures S2A,B in Supplementary Material). Therefore, the results suggest that $\mathrm{HP}-\beta-\mathrm{CD}$ potentiates the ability of DCs to induce $\mathrm{CD} 4^{+}$cells.

\section{HP- $\beta-C D$ Triggers Lipid Raft Formation on the DC Plasma Membrane}

Lipid rafts are hydrophobic microstructures that play an important role as signal transduction platforms in many eukaryotic cells (20). Since HP- $\beta$-CD interacts with cellular cholesterol (21), an essential component of lipid rafts, we examined whether $\mathrm{HP}-\beta-\mathrm{CD}$ induces lipid raft formation on the plasma membrane based on the hypothesis that lipid rafts are involved in the HP- $\beta$-CD-induced DC maturation. DCs were stimulated with HP- $\beta$-CD in the presence or absence of filipin, which disrupts

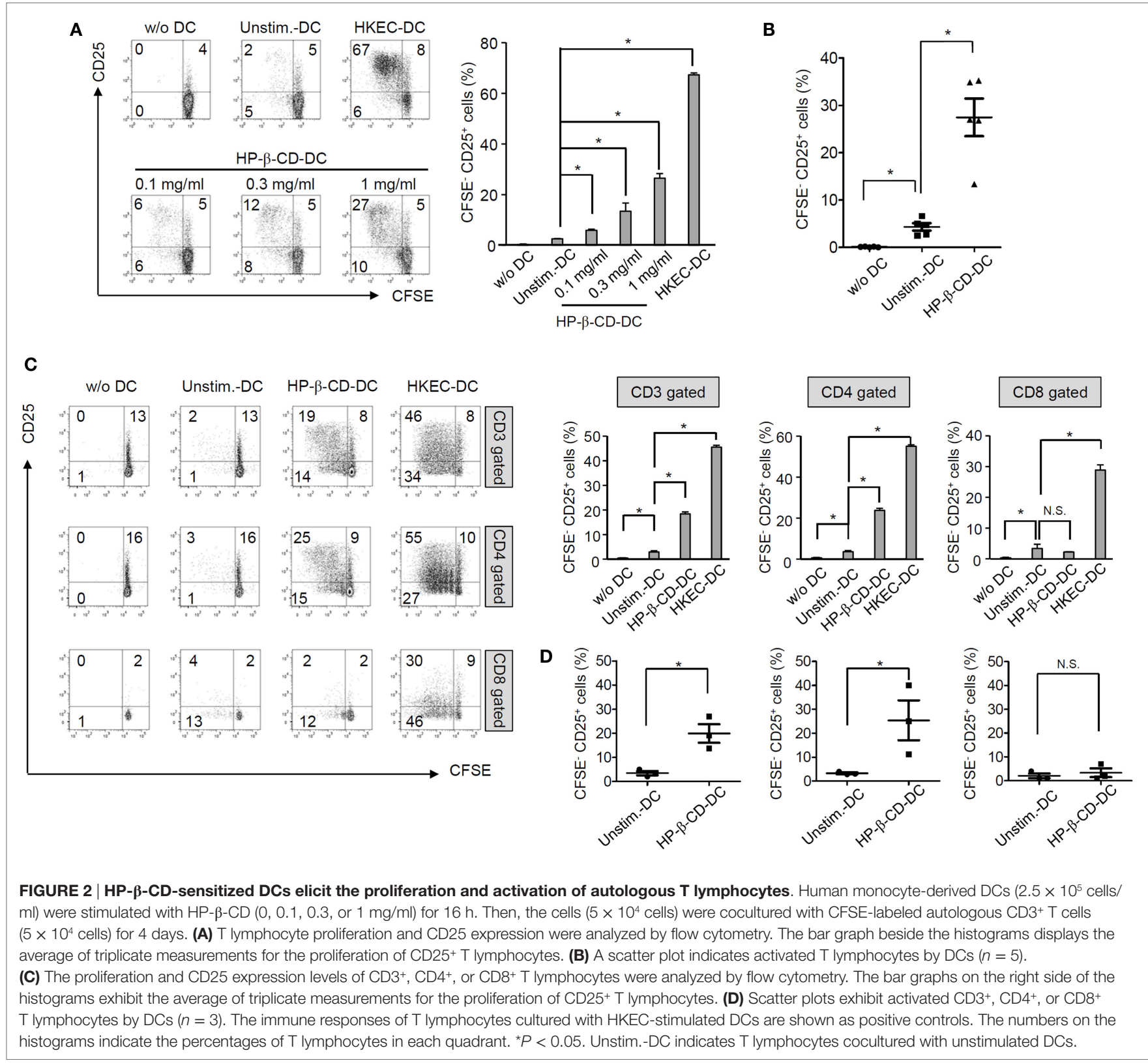


a lipid raft formation, and fluorochrome-conjugated CTB was used to detect the formation of lipid rafts. As shown in Figure 3, $\mathrm{HP}-\beta$-CD triggered lipid raft formation on the surface of DCs, whereas such effect was blocked by preexposure to the lipid raft inhibitor filipin.

\section{Inhibition of Lipid Raft Formation Reduces HP- $\beta$-CD-Induced DC Maturation}

Next, we further determined the role of lipid rafts in HP- $\beta$-CDmediated DC maturation by blocking the lipid raft formation using filipin. Of note, treatment with filipin and/or HP- $\beta$-CD was not cytotoxic to DCs (Figure S1B in Supplementary Material). As shown in Figures $\mathbf{4 A - C}$, treatment with filipin remarkably attenuated HP- $\beta$-CD-elicited expression of surface costimulatory molecules, PD-L1/L2, but not MHC class II. In addition, HP- $\beta$-CD-mediated induction of TNF- $\alpha$, IL- 6 , and IL-10 in DCs was significantly reduced upon the inhibition of lipid raft (Figure 4D). Furthermore, lipid raft inhibition in DCs stimulated with HP- $\beta$-CD abrogated their ability to activate T lymphocytes (Figure 4E). These results suggest that HP- $\beta-C D$ requires the formation of lipid rafts to trigger DC maturation and further to activate $\mathrm{T}$ lymphocytes.

\section{HP- $\beta$-CD Potentiates Humoral Immune Responses to Coadministered Antigens and DC Activation in the Draining Lymph Nodes in Mice}

Next, we determined whether HP- $\beta$-CD has an adjuvanticity with a mouse footpad immunization model (22). To immunize mice, OVA with or without HP- $\beta$-CD was injected through a hind footpad, and titers of serum antibodies specific to OVA were determined. Coadministration with HP- $\beta-\mathrm{CD}$ and OVA efficiently increased OVA-specific total IgG in the blood (Figure S3A in Supplementary Material). IgG1 was the major antibody subtype induced following immunization (Figure S3B in Supplementary Material), and no IgG2a antibodies were detected (data not shown). As DCs are crucial in the mediation of naive $\mathrm{T}$ cell responses, we subsequently analyzed DC populations in the draining lymph nodes, including popliteal and inguinal lymph nodes upon administration of OVA with or without HP- $\beta$-CD. Mice administered with OVA with HP- $\beta$-CD showed an increase in the size and cell number of the draining lymph nodes (Figure 5A). OVA administration with HP- $\beta$-CD markedly augmented the number of $\mathrm{CD} 11 \mathrm{c}^{+}$ MHC class $\mathrm{II}^{+}$cells in the popliteal and inguinal lymph nodes (Figures 5B,C). In addition, the DCs showed an upregulation in the expression of costimulatory molecules, including CD80 and CD86 (Figures 5D,E). To determine whether DC activation in the draining lymph nodes of mice administered with OVA and $\mathrm{HP}-\beta-\mathrm{CD}$ is directly attributed to stimulatory functions of HP- $\beta$-CD, we examined HP- $\beta$-CD effects on the maturation of $\mathrm{BM}-\mathrm{DC}$ generated in vitro. HP- $\beta$-CD markedly upregulated the expression of surface costimulatory molecules, such as CD80, CD83, and CD86, and MHC class II (Figure 5F). In addition, HP- $\beta$-CD-treated BM-DCs modestly increased the production of proinflammatory cytokines including TNF- $\alpha$ and IL- 6 in BM-DCs compared to LPS-stimulated BM-DCs (Figure 5G). Collectively, these results suggest that HP- $\beta$-CD-induced DC maturation and activation in vivo that might be necessary for the adjuvanticity.

\section{DISCUSSION}

Dendritic cells play a pivotal role in the induction of antigenspecific adaptive immune response by presenting the antigens to
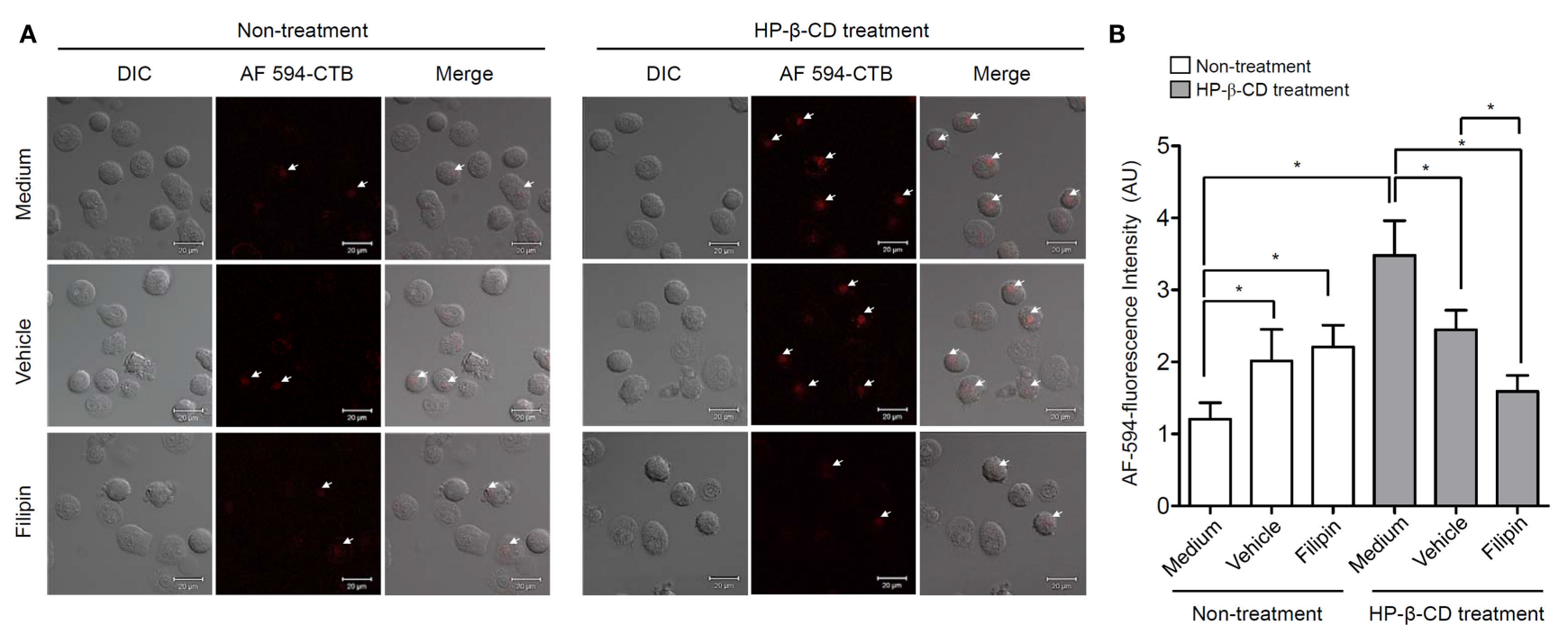

FIGURE 3 | HP- $\boldsymbol{\beta}$-CD triggers lipid raft formation in DCs. Human monocyte-derived DCs $\left(2.5 \times 10^{5}\right.$ cells $\left./ \mathrm{ml}\right)$ were stimulated with $\mathrm{HP}-\beta-\mathrm{CD}(1 \mathrm{mg} / \mathrm{ml})$ in the presence or absence of filipin $(30 \mu \mathrm{g} / \mathrm{ml})$ or methanol as a vehicle control for $45 \mathrm{~min}$. (A) Stimulated DCs were stained with Alexa Fluor ${ }^{\circledR} 594-\mathrm{conjugated}$ CTB, and the formation of lipid rafts on the cell surface was examined by confocal microscopy. (B) Fluorescence intensity of DCs was analyzed by ZEN software. DIC, differential interference contrast; AU, arbitrary unit. Images shown are representative of three similar results. 


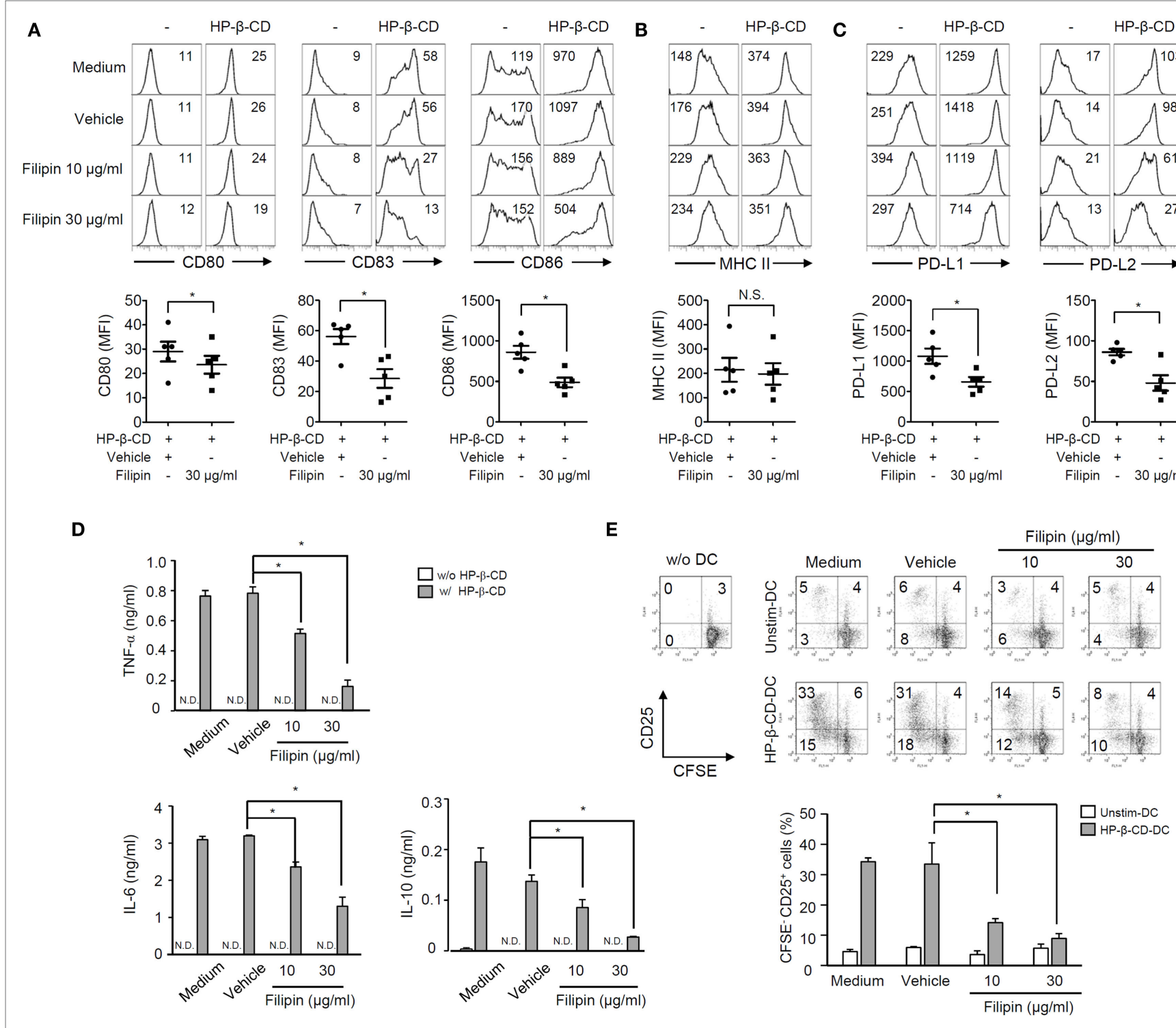

FIGURE 4 | Inhibition of lipid raft formation attenuates DC maturation, cytokine production, and autologous T cell activation induced by HP- $\beta$-CD. Human monocyte-derived DCs $\left(2.5 \times 10^{5} \mathrm{cells} / \mathrm{ml}\right)$ were pretreated with filipin (10 and $\left.30 \mu \mathrm{g} / \mathrm{ml}\right)$ or methanol as a vehicle control for $1 \mathrm{~h}$, followed by stimulation with HP- $\beta$-CD $(1 \mathrm{mg} / \mathrm{ml})$ for another $24 \mathrm{~h}$. (A-C) The expression of costimulatory molecules, MHC class II, and PD-L1/L2 was analyzed by flow cytometry. The numbers on the histograms indicate the MFIs of the cells. Scatter plots under the histogram show MFI of DCs $(n=5)$. Statistical differences between compared groups were analyzed by paired Student's $t$-test. N.S., not significant; ${ }^{*} P<0.05$. (D) The concentrations of TNF- $\alpha$, IL-6, and IL-10 in the supernatants were measured by ELISA. (E) Unstimulated or HP- $\beta$-CD-stimulated DCs $\left(5 \times 10^{4}\right.$ cells) were cocultured with CFSE-labeled autologous T lymphocytes $\left(5 \times 10^{4}\right.$ cells) for 5 days. The levels of proliferation and CD25 expression of the T lymphocytes were analyzed by flow cytometry. The numbers on the histograms indicate the percentages of cells in each quadrant. The bar graph below the histograms displays the average of triplicate measurements \pm SD for the frequencies of CD25+ $T$ lymphocytes with proliferative ability. Unstim.-DC indicates T lymphocytes cocultured with unstimulated DCs. Results shown are representative of three independent experiments. Statistical differences between compared groups were analyzed by Student's $t$-test. N.D., not detected; ${ }^{*} P<0.05$.

T cells and activating appropriate subtypes of T cells. HP- $\beta-C D$ has long been utilized as a solubilizer and a delivery compound of hydrophobic drugs due to its physicochemical properties (6). However, recent studies have reported a novel beneficial effect of HP- $\beta$-CD on the immunogenicity of vaccines $(7,23)$ as well as on the progression of incurable metabolic disorders (24) and viral infections (25). Although the previous findings have suggested that HP- $\beta$-CD could be a potential vaccine adjuvant $(7,23)$, the effects of HP- $\beta$-CD on vaccine immunogenicity and DC properties have been poorly investigated. Here, we demonstrated that HP- $\beta$-CD has an adjuvanticity to OVA, and the maturation of DCs found in the draining lymph nodes in a mouse footpad immunization model. In vitro studies showed that HP- $\beta$-CD induces the maturation of DCs to induce the proliferation and activation of autologous $\mathrm{T}$ lymphocytes. Mechanism studies further showed that the lipid raft formation in DCs is essential for 


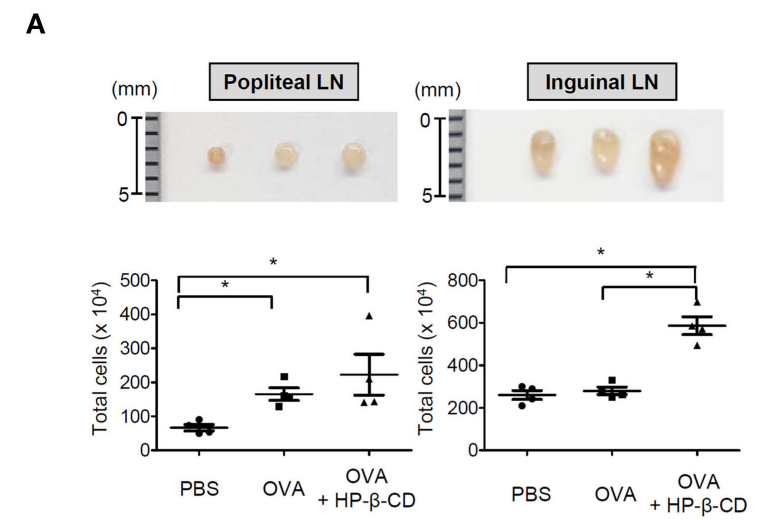

D
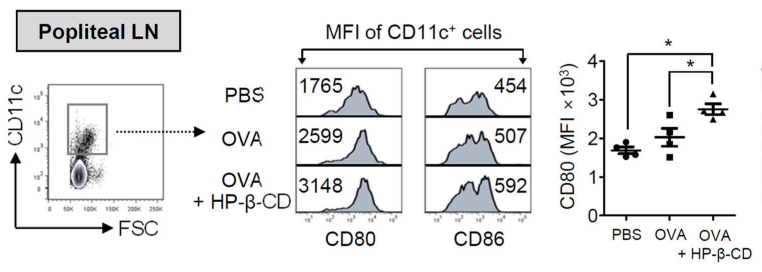

E

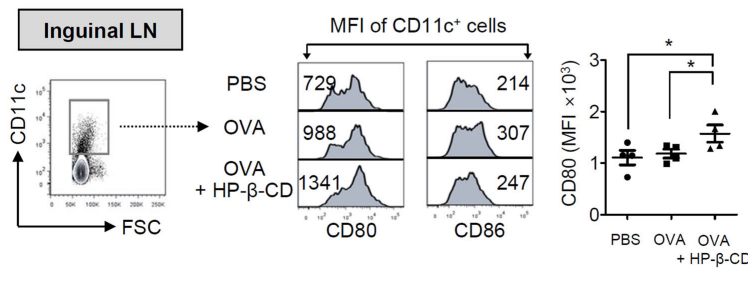

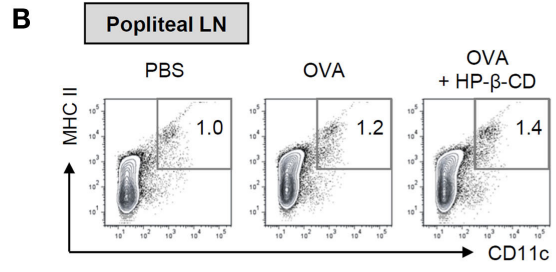
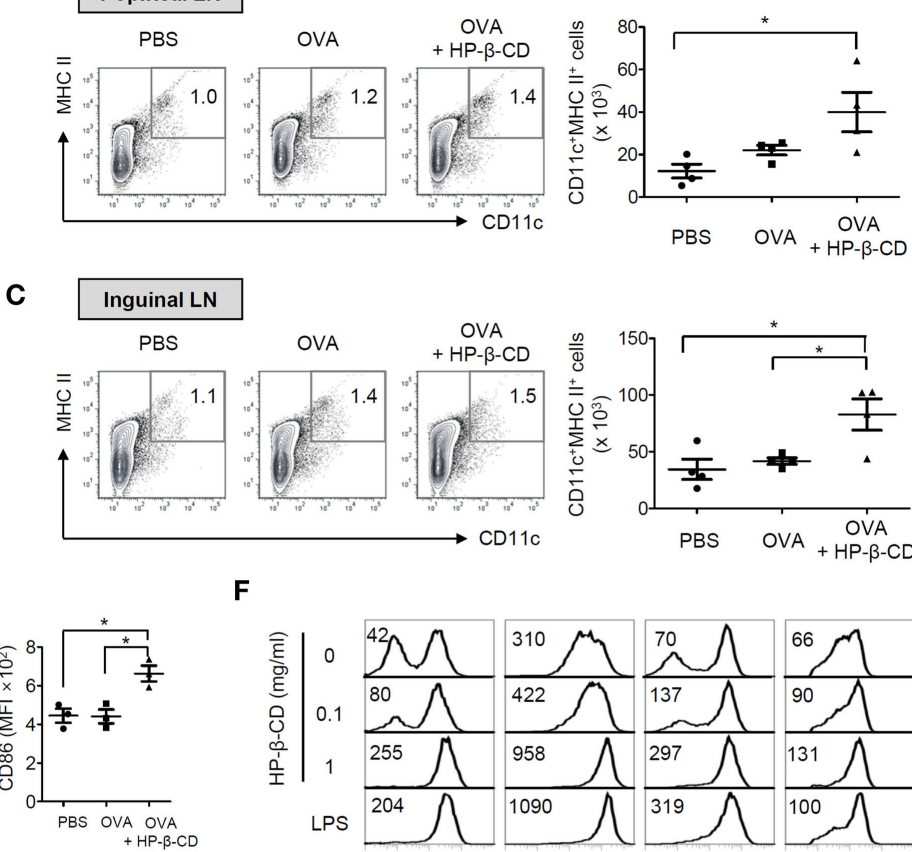

$\mathbf{F}$

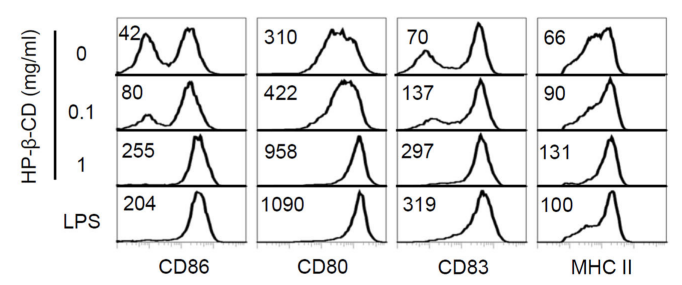

G
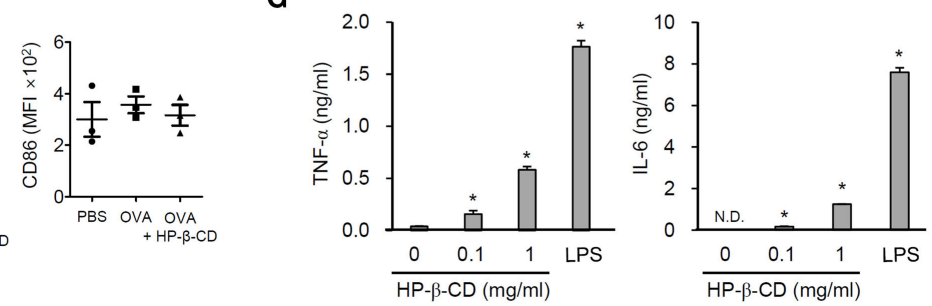

FIGURE 5 | HP- $\beta$-CD induces DC maturation and activation in vivo and in vitro mouse models. C57BL/6 mice were immunized with $20 \mu \mathrm{g}$ OVA in the presence or absence of $3 \mathrm{mg} \mathrm{HP}-\beta-\mathrm{CD}$ through a hind footpad. Twenty-four hours after the immunization, DC populations were analyzed in the draining lymph nodes including popliteal and inguinal lymph nodes. (A) Size of the lymph nodes and the total cell numbers were measured $(n=4)$. CD11 $\mathrm{C}^{+} \mathrm{MHC}$ class $\|^{+}$cells in the draining lymph nodes, (B) popliteal and (C) inguinal lymph nodes were analyzed by flow cytometry $(n=4)$. Expression of CD80 and CD86 on CD11 ${ }^{+}$cells was analyzed in the draining lymph nodes, (D) popliteal and (E) inguinal lymph nodes by flow cytometry. Scatter plots on the right side the histograms indicate MFI of DCs for CD80 $(n=4)$ and CD86 $(n=3)$. (F) BM-DCs $\left(5 \times 10^{5}\right.$ cells $\left./ \mathrm{ml}\right)$ were stimulated with HP- $\beta$-CD $(0.1$ or $1 \mathrm{mg} / \mathrm{ml})$ or LPS $(100 \mathrm{ng} / \mathrm{ml})$ in the presence of murine GM-CSF for $24 \mathrm{~h}$. The surface expression of various maturation markers, including (F) CD80, CD83, CD86, and MHC class II molecules on the DCs, was analyzed by flow cytometry. (G) The amounts of TNF- $\alpha$ and IL-6 in the culture supernatants of DCs were quantified by ELISA. The number on each histogram indicates percentage or MFI of the DCs. LN, lymph node. N.D., not detected. N.S., not significant. ${ }^{*} P<0.05$. The result shown is a representative of four similar experiments.

the HP- $\beta$-CD-induced DC maturation and its subsequent activation of autologous $\mathrm{T}$ cells. These results suggest that HP- $\beta-\mathrm{CD}$ is a promising vaccine adjuvant to potently induce the maturation and activation of DCs.

In the present study, we demonstrated that HP- $\beta$-CD has an adjuvanticity. Administration of HP- $\beta$-CD efficiently augmented the antigen-specific IgG in the blood. Notably, HP- $\beta$-CD predominantly induced IgG1 but not IgG2, indicating preferential enhancement of Th2 responses rather than Th1 responses. Consistent with our findings, intranasal or subcutaneous administration of HP- $\beta$-CD increased the immunogenicity of influenza vaccines $(7,23)$. HP- $\beta$-CD seems to be appropriate as a mucosal adjuvant because it induces antigen-specific IgA and IgG in the airway mucosal tissues as well as in the blood (23).
Dendritic cell maturation is a prerequisite for the induction of adaptive immune response. Many previous studies have demonstrated that current vaccine adjuvants, such as aluminum salt (alum), cholera toxin (CT), and monophosphoryl lipid A (MPLA), can efficiently induce DC maturation (26-28). Here, we observed that HP- $\beta$-CD increased DCs in the draining lymph nodes as well as the upregulation of DC costimulatory molecules when coadministered with antigen. Additionally, HP- $\beta-C D$ induced a marked increase in the expression of CD80, CD83, CD86, and MHC proteins on BM-DCs and human monocytederived DCs. Furthermore, stimulation with HP- $\beta-C D$ resulted in weak but significant production of TNF- $\alpha$, IL- 6 , and IL-10 in DCs. Therefore, like other adjuvants, HP- $\beta$-CD appears to be capable of stimulating DC maturation. However, in contrast to our 
observation, a previous study found that HP- $\beta$-CD did not induce a maturation marker of CD11 $\mathrm{c}^{+} \mathrm{DCs}$ in the draining lymph node, even though it potentiated DC antigen uptake (7). Given the differences in a route of injection and doses of HP- $\beta$-CD, functional mode of DC activation in the tissues might be different.

Here, we found that HP- $\beta$-CD-sensitized DCs markedly induced the proliferation and activation of $\mathrm{T}$ lymphocytes, especially $\mathrm{CD}^{+}$cells, implying that $\mathrm{HP}-\beta-\mathrm{CD}$ can potentially enhance Th-dependent immune responses. Notably, a study of mice immunized with an influenza vaccine suggested that HP- $\beta-\mathrm{CD}$ is a competent adjuvant capable of eliciting follicular Th cells and antibody production (7). Furthermore, other cyclodextrins, such as sulfolipo-cyclodextrin and dimethyl- $\beta$ cyclodextrin, have been found to enhance antibody responses in a $\mathrm{T}$ lymphocyte-dependent manner $(29,30)$. Given the fact that enhanced $\mathrm{T}$ cell responses have previously been observed with many existing adjuvants, including MPLA, saponin, and CT $(31,32)$, this enhancement appeared to be mediated through DC activation. These adjuvants influence the types of adaptive immune responses that occur by modulating $\mathrm{T}$ lymphocyte differentiation. For instance, alum is an established potentiator of Th2-mediated humoral immunity (33). In addition, MPLA has been shown to preferentially induce Th1-skewed immune responses (34), whereas CT provokes Th1, Th17, and Th2 responses (35). Considering the previous finding that HP- $\beta-C D$ administration markedly induces IL-13 and IL- 5 production, HP- $\beta$-CD has been proposed to elicit Th 2 responses (7).

In the present study, we observed that $\mathrm{HP}-\beta$-CD-induced lipid raft formation and contributed to DC maturation. Specifically, filipin-mediated inhibition of lipid rafts abrogated HP- $\beta$-CDmediated phenotypic changes and functional activation of DCs. In line with this observation, many previous studies have demonstrated lipid raft involvement in the activation of various immune cells. Dispersion of lipid rafts has been shown to impair CD1a-mediated antigen presentation by DCs and subsequent activation of T lymphocytes (36). Furthermore, alum adjuvanticity has been proposed to have a critical relationship with the formation of signaling platforms via lipid sorting on DCs (26).

2 -Hydroxypropyl- $\beta$-cyclodextrin can interact with cellular cholesterol (21); however, the precise effects of HP- $\beta$-CD on cholesterol seem to depend on its concentration. Low doses of HP- $\beta$-CD (below $1 \mathrm{mM}$ ) induce efflux or intermembrane transport of cholesterol, while high concentrations (10-100 mM) deplete the lipid molecules from the cell membrane $(37,38)$. In the

\section{REFERENCES}

1. Loftsson T, Brewster ME. Pharmaceutical applications of cyclodextrins.1. Drug solubilization and stabilization. JPharm Sci (1996) 85:1017-25. doi:10.1021/Js950534b

2. Rawat S, Jain SK. Solubility enhancement of celecoxib using beta-cyclodextrin inclusion complexes. Eur J Pharm Biopharm (2004) 57:263-7. doi:10.1016/ j.ejpb.2003.10.020

3. Jin $\mathrm{X}$, Zhang ZH, Sun E, Jia XB. beta-cyclodextrin assistant flavonoid glycosides enzymatic hydrolysis. Pharmacogn Mag (2013) 9:11-8. doi:10.4103/0973-1296.117851

4. Kurkov SV, Loftsson T. Cyclodextrins. Int J Pharm (2013) 453:167-80. doi:10.1016/j.ijpharm.2012.06.055 present study, DCs were treated with up to $1 \mathrm{mg} / \mathrm{ml} \mathrm{HP}-\beta-\mathrm{CD}$, which is equivalent to $1.4 \mathrm{mM}$. This concentration is relatively low and is likely to mediate cholesterol accumulation and lipid raft formation on the cell membrane rather than to deplete cholesterol. In light of the observation that cholesterol accumulation in the membrane of human monocytes promotes the association of immuno-stimulatory receptor complexes, cholesterol loading in the plasma membrane is believed to be crucial for eliciting inflammatory immune responses (39). Since HP- $\beta$-CD can transport free cholesterol to the plasma membrane (40), HP- $\beta-C D$ is likely to play a role in the formation of cholesterol-rich lipid rafts in DCs, thereby activating signals required for their phenotypic and functional maturation.

Recently, potential issues in relation to the efficacy and safety of vaccine adjuvant have been raised (41-44). Thus, demand has increased for new adjuvants with minimal adverse effects and enhanced capacity to stimulate antigen-specific adaptive immune responses. HP- $\beta-\mathrm{CD}$ is GRAS in many Asian and European countries and is already widely utilized in various commercial products, including food and drugs. Our findings potentially inform the future application and improvement of vaccine adjuvants with $\mathrm{HP}-\beta-\mathrm{CD}$.

\section{AUTHOR CONTRIBUTIONS}

SH conceived the idea. SH and SK designed the experiments. SK and $\mathrm{SH}$ performed the experiments and/or interpreted the data. C-HY provided critical comments. All authors contributed to discussion of the results followed by writing and reviewing the manuscript.

\section{FUNDING}

This work was supported by grants from the National Research Foundation of Korea (2015M2A2A6A01044894 and 2015R1A2A1A15055453) and the Korea Health Technology R\&D Project through the Korea Health Industry Development Institute (KHIDI), which is funded by the Ministry of Health \& Welfare (HI14C0469), Republic of Korea.

\section{SUPPLEMENTARY MATERIAL}

The Supplementary Material for this article can be found online at http://journal.frontiersin.org/article/10.3389/fimmu.2016.00435

5. Brewster ME, Loftsson T. Cyclodextrins as pharmaceutical solubilizers. Adv Drug Deliv Rev (2007) 59:645-66. doi:10.1016/j.addr.2007.05.012

6. Loftsson T, Jarho P, Masson M, Jarvinen T. Cyclodextrins in drug delivery. Expert Opin Drug Deliv (2005) 2:335-51. doi:10.1517/17425247.2.1.335

7. Onishi M, Ozasa K, Kobiyama K, Ohata K, Kitano M, Taniguchi K, et al. Hydroxypropyl-beta-cyclodextrin spikes local inflammation that induces Th2 cell and T follicular helper cell responses to the coadministered antigen. J Immunol (2015) 194:2673-82. doi:10.4049/jimmunol.1402027

8. Mellman I, Steinman RM. Dendritic cells: specialized and regulated antigen processing machines. Cell (2001) 106:255-8. doi:10.1016/ S0092-8674(01)00449-4

9. Fang H, Ang B, Xu X, Huang X, Wu Y, Sun Y, et al. TLR4 is essential for dendritic cell activation and anti-tumor T-cell response enhancement by 
DAMPs released from chemically stressed cancer cells. Cell Mol Immunol (2014) 11:150-9. doi:10.1038/cmi.2013.59

10. Dudek AM, Martin S, Garg AD, Agostinis P. Immature, semi-mature, and fully mature dendritic cells: toward a DC-cancer cells interface that augments anticancer immunity. Front Immunol (2013) 4:438. doi:10.3389/ fimmu.2013.00438

11. Osorio F, Fuentes C, Lopez MN, Salazar-Onfray F, Gonzalez FE. Role of dendritic cells in the induction of lymphocyte tolerance. Front Immunol (2015) 6:535. doi:10.3389/fimmu.2015.00535

12. Kaiko GE, Horvat JC, Beagley KW, Hansbro PM. Immunological decision-making: how does the immune system decide to mount a helper T-cell response? Immunology (2008) 123:326-38. doi:10.1111/j.1365-2567.2007. 02719.x

13. Upchurch KC, Boquin JR, Yin W, Xue Y, Joo H, Kane RR, et al. New TLR7 agonists with improved humoral and cellular immune responses. Immunol Lett (2015) 168:89-97. doi:10.1016/j.imlet.2015.09.007

14. Liu X, Li J, Liu Y, Ding J, Tong Z, Liu Y, et al. Calreticulin acts as an adjuvant to promote dendritic cell maturation and enhances antigen-specific cytotoxic T lymphocyte responses against non-small cell lung cancer cells. Cell Immunol (2016) 300:46-53. doi:10.1016/j.cellimm.2015.12.003

15. Fu Y, Wang T, Xiu L, Shi X, Bian Z, Zhang Y, et al. Levamisole promotes murine bone marrow derived dendritic cell activation and drives Th1 immune response in vitro and in vivo. Int Immunopharmacol (2015) 31:57-65. doi:10.1016/j.intimp.2015.12.015

16. Kim SK, Yun CH, Han SH. Enhanced anti-cancer activity of human dendritic cells sensitized with gamma-irradiation-induced apoptotic colon cancer cells. Cancer Lett (2013) 335:278-88. doi:10.1016/j.canlet.2013.02.038

17. Kim SK, Yun CH, Han SH. Dendritic cells differentiated from human umbilical cord blood-derived monocytes exhibit tolerogenic characteristics. Stem Cells and Dev (2015) 24:2796-807. doi:10.1089/scd.2014.0600

18. Reshma CS, Sruthi S, Syama S, Gayathri V, Mohanan PV. Assessing the systemic toxicity in rabbits after sub acute exposure to ocular irritant chemicals. Toxicol Res (2015) 31:49-59. doi:10.5487/TR.2015.31.1.049

19. Khayrullina T, Yen JH, Jing H, Ganea D. In vitro differentiation of dendritic cells in the presence of prostaglandin E2 alters the IL-12/IL-23 balance and promotes differentiation of Th17 cells. J Immunol (2008) 181:721-35. doi:10.4049/jimmunol.181.1.721

20. Staubach S, Hanisch FG. Lipid rafts: signaling and sorting platforms of cells and their roles in cancer. Expert Rev Proteomics (2011) 8:263-77. doi:10.1586/ EPR.11.2

21. Christian AE, Haynes MP, Phillips MC, Rothblat GH. Use of cyclodextrins for manipulating cellular cholesterol content. J Lipid Res (1997) 38:2264-72.

22. Kamala T. Hock immunization: a humane alternative to mouse footpad injections. J Immunol Methods (2007) 328:204-14. doi:10.1016/j.jim.2007.08.004

23. Kusakabe T, Ozasa K, Kobari S, Momota M, Kishishita N, Kobiyama K, et al. Intranasal hydroxypropyl-beta-cyclodextrin-adjuvanted influenza vaccine protects against sub-heterologous virus infection. Vaccine (2016) 34:3191-8. doi:10.1016/j.vaccine.2016.04.001

24. Tanaka Y, Yamada Y, Ishitsuka Y, Matsuo M, Shiraishi K, Wada K, et al. Efficacy of 2-hydroxypropyl-beta-cyclodextrin in Niemann-Pick disease type C model mice and its pharmacokinetic analysis in a patient with the disease. Biol Pharm Bull (2015) 38:844-51. doi:10.1248/bpb.b14-00726

25. Senti G, Iannaccone R, Graf N, Felder M, Tay F, Kundig T. A randomized, double-blind, placebo-controlled study to test the efficacy of topical 2-hydroxypropyl-beta-cyclodextrin in the prophylaxis of recurrent herpes labialis. Dermatology (2013) 226:247-52. doi:10.1159/000349991

26. Flach TL, Ng G, Hari A, Desrosiers MD, Zhang P, Ward SM, et al. Alum interaction with dendritic cell membrane lipids is essential for its adjuvanticity. Nat Med (2011) 17:479-87. doi:10.1038/nm.2306

27. Ismaili J, Rennesson J, Aksoy E, Vekemans J, Vincart B, Amraoui Z, et al. Monophosphoryl lipid A activates both human dendritic cells and $\mathrm{T}$ cells. J Immunol (2002) 168:926-32. doi:10.4049/jimmunol.168.2.926

28. Bagley KC, Abdelwahab SF, Tuskan RG, Fouts TR, Lewis GK. Cholera toxin and heat-labile enterotoxin activate human monocyte-derived dendritic cells and dominantly inhibit cytokine production through a cyclic AMP-dependent pathway. Infect Immun (2002) 70:5533-9. doi:10.1128/ IAI.70.10.5533-5539.2002
29. Romera SA, Hilgers LA, Puntel M, Zamorano PI, Alcon VL, Dus Santos MJ, et al. Adjuvant effects of sulfolipo-cyclodextrin in a squalane-in-water and water-in-mineral oil emulsions for BHV-1 vaccines in cattle. Vaccine (2000) 19:132-41. doi:10.1016/S0264-410X(00)00104-3

30. Alpar HO, Eyles JE, Williamson ED, Somavarapu S. Intranasal vaccination against plague, tetanus and diphtheria. Adv Drug Deliv Rev (2001) 51:173-201. doi:10.1016/S0169-409X(01)00166-1

31. Didierlaurent AM, Collignon C, Bourguignon P, Wouters S, Fierens K, Fochesato $\mathrm{M}$, et al. Enhancement of adaptive immunity by the human vaccine adjuvant AS01 depends on activated dendritic cells. J Immunol (2014) 193:1920-30. doi:10.4049/jimmunol.1400948

32. Bagley KC, Abdelwahab SF, Tuskan RG, Lewis GK. Cholera toxin indirectly activates human monocyte-derived dendritic cells in vitro through the production of soluble factors, including prostaglandin $\mathrm{E}(2)$ and nitric oxide. Clin Vaccine Immunol (2006) 13:106-15. doi:10.1128/CVI.13.1.106115.2006

33. Bungener L, Geeraedts F, Ter Veer W, Medema J, Wilschut J, Huckriede A. Alum boosts TH2-type antibody responses to whole-inactivated virus influenza vaccine in mice but does not confer superior protection. Vaccine (2008) 26:2350-9. doi:10.1016/j.vaccine.2008.02.063

34. Wheeler AW, Marshall JS, Ulrich JT. A Th1-inducing adjuvant, MPL, enhances antibody profiles in experimental animals suggesting it has the potential to improve the efficacy of allergy vaccines. Int Arch Allergy Immunol (2001) 126:135-9. doi:10.1159/000049504

35. Mattsson J, Schon K, Ekman L, Fahlen-Yrlid L, Yrlid U, Lycke NY. Cholera toxin adjuvant promotes a balanced $\mathrm{Th} 1 / \mathrm{Th} 2 / \mathrm{Th} 17$ response independently of IL-12 and IL-17 by acting on Gsalpha in CD11b(+) DCs. Mucosal Immunol (2015) 8:815-27. doi:10.1038/mi.2014.111

36. Barral DC, Cavallari M, McCormick PJ, Garg S, Magee AI, Bonifacino JS, et al. $\mathrm{CD} 1 \mathrm{a}$ and MHC class I follow a similar endocytic recycling pathway. Traffic (2008) 9:1446-57. doi:10.1111/j.1600-0854.2008.00781.x

37. McCauliff LA, Xu Z, Storch J. Sterol transfer between cyclodextrin and membranes: similar but not identical mechanism to NPC2-mediated cholesterol transfer. Biochemistry (2011) 50:7341-9. doi:10.1021/bi200574f

38. Atger VM, Moya MD, Stoudt GW, Rodrigueza WV, Phillips MC, Rothblat GH. Cyclodextrins as catalysts for the removal of cholesterol from macrophage foam cells. J Clin Invest (1997) 99:773-80. doi:10.1172/Jci119223

39. Triantafilou M, Miyake K, Golenbock DT, Triantafilou K. Mediators of innate immune recognition of bacteria concentrate in lipid rafts and facilitate lipopolysaccharide-induced cell activation. J Cell Sci (2002) 115:2603-11.

40. Yancey PG, Rodrigueza WV, Kilsdonk EP, Stoudt GW, Johnson WJ, Phillips MC, et al. Cellular cholesterol efflux mediated by cyclodextrins. Demonstration of kinetic pools and mechanism of efflux. J Biol Chem (1996) 271:16026-34. doi:10.1074/jbc.271.27.16026

41. Gherardi RK. [Lessons from macrophagic myofasciitis: towards definition of a vaccine adjuvant-related syndrome]. Rev Neurol (2003) 159:162-4.

42. Asa PB, Cao Y, Garry RF. Antibodies to squalene in Gulf War syndrome. Exp Mol Pathol (2000) 68:55-64. doi:10.1006/exmp.1999.2295

43. Bagavant H, Nandula SR, Kaplonek P, Rybakowska PD, Deshmukh US. Alum, an aluminum-based adjuvant, induces Sjogren's syndrome-like disorder in mice. Clin Exp Rheumatol (2014) 32:251-5.

44. Verstraeten T, Descamps D, David MP, Zahaf T, Hardt K, Izurieta P, et al. Analysis of adverse events of potential autoimmune aetiology in a large integrated safety database of AS04 adjuvanted vaccines. Vaccine (2008) 26:6630-8. doi:10.1016/j.vaccine.2008.09.049

Conflict of Interest Statement: The authors declare that the research was conducted in the absence of any commercial or financial relationships that could be construed as a potential conflict of interest.

Copyright $\odot 2016 \mathrm{Kim}$, Yun and Han. This is an open-access article distributed under the terms of the Creative Commons Attribution License (CC BY). The use, distribution or reproduction in other forums is permitted, provided the original author(s) or licensor are credited and that the original publication in this journal is cited, in accordance with accepted academic practice. No use, distribution or reproduction is permitted which does not comply with these terms. 